\title{
O LEITOR E O JORNALISTA COMO INTERLOCUTORES DOS PROJETOS EDITORIAIS DA FOLHA DE S. PAULO
}

\section{THE READER AND THE JOURNALIST AS INTERLOCUTORS IN THE EDITORIAL PROJECTS OF FOLHA DE S. PAULO}

\author{
Assunção Cristóvão ${ }^{1}$ \\ UNINCOR - Universidade do Vale do Rio Verde
}

\begin{abstract}
RESUMO: Este artigo tem por objetivo refletir sobre as relações de interlocução mantidas entre os projetos editoriais do jornal Folha de S. Paulo com seus jornalistas, considerados interlocutores diretos, e seus leitores, interlocutores indiretos. Foram analisados, a partir dos conceitos de gênero e dialogismo do Círculo de Bakhtin, os sete projetos editoriais disponibilizados pelo jornal para o público (os de 1981, 1984, 1985, 1986, 1988 e 1997 (FOLHA DE S. PAULO, 2010), além de excertos do projeto de 1978, disponíveis em três publicações do jornalista Carlos Eduardo Lins da Silva (1987: passim; 1988: passim; 2005: passim) e uma cópia do projeto de 1982, que nunca chegou a vigorar oficialmente, mas que também consta da obra de Lins da Silva (1987, p. 168-175).
\end{abstract}

PALAVRAS-CHAVE: Projeto editorial; interlocução; jornalismo.

ABSTRACT: This paper aims at reflecting on the interlocutory relations between the Folha de S. Paulo editorial projects and its journalists, here considered direct interlocutors, and its readers, indirect interlocutors. Seven editorial projects, which have been made available to the public, have been analyzed, based on Bakhtin's Circle concepts of genre and dialogism (the ones form 1981, 1984, 1985, 1986, 1988, 1997 (FOLHA DE S. PAULO, 2010)), as well as excerpts from the project from 1978, made available in three publications by the journalist Carlos Eduardo Lins da Silva (1987: passim; 1988: passim; 2005: passim) and a copy from the project from 1982, which never got to be officially valid, but also appears in Lins da Silva's work (1987, p. 168-175).

KEYWORDS: Editorial projetcts; interlocutory; journalism.

\footnotetext{
${ }^{1}$ Docente do Curso de Mestrado em Letras - Linguagem, Cultura e Discurso da Universidade do Vale do Rio Verde - Unincor. Líder do Grupo de Estudos Práticas Discursivas na Contemporaneidade.
} 


\section{INTRODUÇÃO}

Um texto não é obra de um só autor, não é fechado, nem acabado, nem tem sua autoria limitada; nele várias vozes circulam, movimentam-se. É, então, dialógico. O diálogo se traduz pela forma de se posicionar dos sujeitos, seus pontos de vista, a forma de transmitir e projetar o discurso.

No contato com o outro, o indivíduo se coloca sempre a partir do seu espaço social, das suas relações de poder - na família, no trabalho, com os amigos, na sociedade, na hierarquia social. Em cada campo, em cada esfera, haverá uma posição "permitida", uma possibilidade de diálogo, de comunicação, de interação, que levará sempre em conta a posição e o lugar do outro o qual é parte fundamental nesse processo, pois é a partir dele e de seu "lugar" nesse processo que se estabelecerá o discurso.

Para Bakhtin, o termo diálogo, em seu sentido estrito, é compreendido como "uma das formas, é verdade que das mais importantes, da interação verbal" (BAKHTIN, 1999, p. 123). Num sentido amplo, o termo se estende para "não apenas como a comunicação em voz alta, de pessoas colocadas face a face, mas toda comunicação verbal, de qualquer tipo que seja" (p. 123).

As contribuições teóricas dessa perspectiva dialógica permitem, então, encarar os projetos editoriais da Folha de S. Paulo como gêneros discursivos, cada exemplar como ato responsivo único e particular, mas, ao mesmo tempo, como uma retomada de discursos outros, intensamente repetidos num processo sem início nem fim. Gêneros discursivos porque mantêm estabilidades, embora relativas, e, paradoxalmente, porque nunca se repetem. Gêneros que se fundamentam num conceito dialógico, uma vez que, naquilo que têm de novo e de velho, são perguntas e respostas ao mesmo tempo. Cada projeto é formulado como resposta a uma necessidade de mudança constatada por seus produtores/autores e, dessa forma, constitui-se um ato responsivo à maneira de que fala Bakhtin. Ao mesmo tempo, gera respostas de seus interlocutores, constituindo-se, portanto, como diálogo, ainda que não aquele efetuado face a face.

É assim com os projetos editoriais da Folha de S. Paulo, um gênero textual pouco conhecido porque tem como uma de suas principais características o fato de ser restrito aos funcionários internos de veículos de comunicação, algumas vezes somente aos pertencentes aos cargos mais elevados dessas empresas. Segundo Otávio Frias Filho (apud ABREU; LATTMAN-WELTMAN; ROCHA, 2003, p. 370), o projeto editorial é concebido como "um texto que sintetiza a visão que o jornal está tendo sobre o jornalismo mesmo, sobre os objetivos, as metas, os problemas a superar, etc. Esse texto, de certa forma, atualiza os pressupostos, os métodos, os objetivos que o jornal procura alcançar". Para Silva, esses projetos visam ainda a determinar as feições "ideológicas, políticas e técnicas" do jornal (SILVA, 1988, p.68). De forma geral, os projetos representam um espaço de exposição de princípios da empresa, que deverão ser seguidos pelos profissionais de várias áreas, de forma a estabelecer uma unidade na forma como o veículo será visto por seu público e pela sociedade.

Cada veículo de comunicação tem uma maneira própria de delegar a autoria do seu projeto editorial. No caso da Folha, sua autoria é representada pelo Conselho Editorial do jornal, composto por um grupo de pessoas de confiança dos diretores da empresa, com jornalistas e não jornalistas.

Todas essas vozes deixam marcas no textos, pistas a respeito do "eu", daquele que enuncia e das vozes que carrega com ele. Ao mesmo tempo, o sujeito do discurso 
antecipa a resposta do seu interlocutor para argumentar, explorar um assunto, marcar sua presença.

Os projetos editoriais têm como uma de suas características principais serem textos restritos a um público interno, composto, quase sempre, por diretores, editores, chefes de reportagem e alguns jornalistas. A Folha de S. Paulo, entretanto, passou a divulgar publicamente os seus projetos a partir da década de 80 do século passado, na esteira de um processo conhecido como Projeto Folha e que gerou, entre outros, os manuais de redação e estilo, sistemas de avaliação internos e os próprios projetos editoriais.

Como documentos de natureza, pelo menos teoricamente, restrita, de uso interno, os projetos editoriais têm, como interlocutor principal, os próprios jornalistas dos veículos de comunicação. Por isso, esta análise escolheu o jornalista como o principal interlocutor desses textos. Ao mesmo tempo, o leitor do jornal é figura de destaque nas preocupações do projeto e do jornal, tendo sido, inclusive, o personagem do principal slogan publicitário da Folha: "De rabo preso com o leitor". Em função disso, o "outro" leitor também foi alvo da análise deste artigo.

\section{O JORNALISTA}

O projeto editorial tem como interlocutor primeiro o jornalista que é funcionário da empresa Folha de S. Paulo e, portanto, responsável por produzir diariamente o conteúdo editorial do jornal.

Para ser o que é, para transmitir o que transmite, para ser produto de fácil e muita vendagem, para atingir o seu leitor/consumidor que, em última instância, mantém o jornal, a Folha precisa orientar seus jornalistas, os verdadeiros produtores dessa mercadoria, ainda que seu caráter de empresa a identifique primeiramente com o consumidor do jornal. Por isso, pode-se dizer que o gênero projeto editorial tem caráter preponderantemente prescritivo, sem, entretanto, deixar de apresentar forte componente argumentativo, persuasório, informativo e outros:

A tendência da direção dos jornais é aliciar os jornalistas para seus propósitos. Mino Carta aponta como o Projeto Folha "não mira o leitor a não ser como segundo alvo, mais distante no espaço e no tempo. O primeiro alvo é o próprio profissional da Folha a ser moldado a 'um novo tipo de jornalismo diário', como dizem os evangelhos [grifo meu] da Barão de Limeira. (grifos do autor) (RIBEIRO, 2001, p. 130).

O jornalista é o alvo, situação que se modifica quando esses textos passam a ser divulgados publicamente. Então, com aquilo que se pode chamar "contaminação de gênero", uma vez que, ao invés de apenas documento prescritivo, de uso interno, os projetos passam a funcionar também como material mercadológico, seu interlocutor também muda: em vez de apenas o jornalista ou o público interno, passa a ser, prioritariamente, o leitor.

Considerando-se o período de mais de 30 anos a partir da confecção do primeiro projeto editorial da Folha, vê-se que ele, de certa forma, coincide, no Brasil, com a passagem de um jornalismo artesanal para outro mais industrial, um processo com o qual aquele jornal colaborou diretamente. O projeto de 85 dizia o seguinte: "O jornalismo não é mais artesanato, mas uma atividade industrial que reivindica método, planejamento, organização e controle".

Sobre essa transição, Cavalcanti (2004, p. 70) afirma que: 
[...] a passagem do jornalismo artesanal para o industrial provoca transformações não apenas na prática como no perfil do jornalista: não mais o boêmio, mas o que deve se submeter a novas regras. O jornalista romântico passa a ser visto como ineficaz, despreparado para enfrentar as crescentes mudanças, como a racionalização dos processos de produção. Isso não significa que há puramente uma substituição, sai de cena o romântico e entra o racional, o metódico, mas que novas discursividades se abrem, possibilitando, assim, que novos elementos entrem na configuração do imaginário do/sobre o jornalista, na constituição de sua identidade.

A Folha cobrava do seu jornalista o desempenho que prescrevia em seus projetos. Logo no projeto de 1981, o documento deixa claro para "os que optarem por permanecer no núcleo dirigente" "que se elevará o nível das exigências e solicitações". No ano seguinte, o jornal vai falar que "a opção radical pela independência está exigindo, de todos nós, grandes esforços e sacrifícios", referindo-se à "luta contra o partidarismo".

Pouco tempo depois, o jornal viveria provavelmente a melhor fase de sua história. Ter sido o precursor, entre os veículos de comunicação brasileiros, da defesa da campanha pelas eleições diretas à presidência da República rendeu ao jornal a liderança no volume de vendas. No projeto de 1984, talvez contaminado pelo clima de efervescência política que dominava o Brasil, a Folha utiliza um termo do universo léxico da política sindical para se referir ao seu jornalista, interlocutor dos projetos - companheiro:

Os companheiros que ocupam cargos de chefia na redação e sucursais devem dedicar menor tempo e atenção aos trabalhos da rotina diária, os quais devem ser delegados aos subordinados que possam responder pelas consequências da execução.

$\mathrm{Ou}:$

Os companheiros que não exercem cargos de chefia precisam investir constantemente em seu próprio desenvolvimento profissional.

O componente afetivo do termo não corresponde ao clima que se vivia na redação. Naquele ano, fruto das avaliações recém implantadas, o jornal demitiu, de uma só vez, 27 jornalistas, cerca de 10\% dos profissionais que trabalhavam na sede, em São Paulo. Em relatório interno, o jornal dizia que "o histórico de sua avaliação profissional revelava incompatibilidade de várias naturezas em relação às expectativas do conjunto das chefias e às demandas de exigência técnica crescente colocadas pelo projeto" (SILVA, 2005, p. 106).

Essa forma pouco sensível de conduzir seu projeto de reformulação interna ressoa no projeto de 84. Àqueles que não são chefes, ou que não correspondem ao padrão de qualidade determinado pelo projeto, a Folha não demonstra dedicar muita paciência. $\mathrm{O}$ documento deixa claro que o profissional ideal não é aquele que se encontra na folha de pagamentos do jornal. O projeto reclama da falta de tempo dos editores para orientar os repórteres e admite que "ainda há um número considerável de jornalistas cuja qualificação profissional não está à altura das exigências colocadas pelo Projeto da Folha". Como o jornal não tem tempo nem condições materiais para "adestrá-los" e "prepará-los" adequadamente, "terão que ser substituídos", segundo o projeto.

A visão que o jornal tem do seu interlocutor e, principalmente, o grau de desempenho que dele espera são outros dois elementos cuja análise esse documento permite Disponível em: http://seer.fclar.unesp.br/casa 
fazer. A começar pelo verbo "adestrar", realçado anteriormente, e mais adequado para referirse ao treinamento com animais.

Segundo Cavalcanti (2006, p. 88):

\begin{abstract}
Nos primeiros documentos, exige-se do profissional a adoção irrestrita de preceitos como a técnica, a organização, a precisão, a neutralidade. Os documentos reiteravam diversas vezes que os profissionais que não adotassem tais regras (a adesão ao projeto) seriam substituídos, o que de fato ocorreu. Nunca houve um período na imprensa em que tantos jornalistas foram demitidos (27 em um único dia), e ainda com a justificativa de não terem qualificações profissionais para continuarem nos cargos ("insuficiência técnica"). Nas palavras de Lins da Silva, um dos mentores do projeto, procurava-se substituir ideologias: no lugar do jornalismo romântico, concebido como uma forma de arte, o jornalismo empresarial, quantitativo. Fica claro aqui onde e em que condições se deu o embate entre as duas formas de conceber o jornalismo.
\end{abstract}

No projeto de 84, inicialmente a Folha elogia seus jornalistas: “[...] na Folha como um todo trabalha um número expressivo de jornalistas talentosos, capazes e dedicados". Logo a seguir, entretanto, o jornal narra as falhas de suas edições: serviços noticiosos precários, qualidade flutuante das edições, erros grosseiros de informação e edição, problemas relacionados, diretamente, ao desempenho dos jornalistas.

$\mathrm{Na}$ seção em que propõe atacar os problemas, a Folha mostra-se exigente e propõe a seus funcionários inúmeras tarefas, como uniformizar critérios editoriais e técnicos, o que deveria ser feito com o Manual de Redação, lançado naquele ano; informar mais e melhor, com textos mais concisos, corretos, objetivos, claros, completos e exatos; planejar antecipadamente as edições; delegar tarefas a subordinados; orientar melhor as equipes; agilizar relacionamento entre editorias e reportagem, sucursal e correspondentes; punir erros e substituir profissionais; hierarquizar assuntos e pautas; etc. Este é o projeto em que, provavelmente, a lista de tarefas, de prescrições é maior entre todos os outros.

Novamente, para a Folha, "quem exige esse zelo é o leitor, ele próprio cada vez mais exigente". Ao transferir para o leitor esse papel, é como se fosse ele o patrão, não a empresa e também fosse o leitor quem cobrasse do funcionário a realização de todas essas tarefas.

Duas posturas ficam evidentes nos projetos desde os primeiros: uma delas é o fato de que, ao dirigir-se ao jornalista, o projeto frequentemente adota não a voz da empresa, mas a do leitor, para exigir atitudes e posturas de seus funcionários, ou pelo menos divide com o leitor, em alguns momentos, essa voz de autoria dos projetos; a outra é a tentativa, sempre presente nos projetos, de identificar competência e profissionalismo com desengajamento, principalmente político. É assim desde os primeiros projetos, como o de 82, por exemplo, quando essas duas posturas podem ser verificadas num único trecho:

[...] profissionalismo é sinônimo de desengajamento. É uma luta sem trégua contra o parti pris, contra o preconceito, contra o senso-comum (daí a ideia do "não é o que parece"), contra a falta de clareza e de concisão, contra as informações incompletas ou ambíguas. O leitor espera, do material noticioso e interpretativo (ao contrário do material opinativo), aquele mínimo de 
isenção jornalística que lhe permita compreender os fatos e suas implicações possíveis ou prováveis.

Em um ano de eleições, é natural que o profissionalismo signifique, sobretudo, a luta contra o partidarismo. (PE 82).

O sentido que se revela é que o projeto de 82 foi escrito principalmente em função das eleições, para deixar clara a mensagem do apartidarismo, uma vez que a maior parte daquele texto é dedicada a esse assunto.

O PE seguinte, de 84, abandona temporariamente o tema do apartidarismo, até porque esse projeto, que tem como foco as Diretas Já, é bastante atípico no conjunto de documentos da Folha, mas não desiste de atribuir ao leitor a responsabilidade pelas inúmeras exigências feitas aos jornalistas. Após elencar um número elevado de atribuições, diz o projeto: "Quem exige esse zelo rigoroso é o interesse do leitor, ele próprio cada vez mais exigente. Nós não temos alternativa exceto a intransigência técnica".

O projeto seguinte, de 85, novamente relaciona o apartidarismo com a responsabilidade e o compromisso da Folha com seus leitores:

Crítica contra tudo e contra todos porque a Folha é e precisa ser radicalmente apartidária. É imaginário supor que o jornal possa emitir compromissos com este ou com aquele setor ideal da sociedade. Sociologicamente, a única base social do jornal é o grupo heterogêneo constituído pelos seus leitores.

O jornal precisa ser apartidário porque a base de leitores é pluripartidária. Vamos atravessar um período eleitoral em que esse distanciamento crítico da Folha em relação a partidos e candidatos tem de ser reforçado.

[...] o exercício do apartidarismo não é uma regalia, mas um encargo.

O tema é retomado no projeto de 86: "Vamos preservar a atitude editorial de apartidarismo". O de 88 "abandona" o tema do apartidarismo, que somente será retomado no de 97.

A luta do projeto será, portanto, contra a tendência partidária de seu interlocutor, que se acentua cada vez que se avizinha e transcorre um período eleitoral, e, por isso, períodos eleitorais são sempre momentos nos quais os projetos são mais incisivos a esse respeito.

Em relação à característica do projeto de adotar a voz que se supõe do leitor como sendo a voz da empresa, a voz de autoria, para exigir posturas dos jornalistas, vale a pena também fazer um retrospecto dos projetos. O de 82 , por exemplo, quando pede o desengajamento, o apartidarismo dos profissionais da casa, expressa-se da seguinte forma:

O leitor espera, do material noticioso e interpretativo (ao contrário do material opinativo), aquele mínimo de isenção jornalística que lhe permita compreender os fatos e suas implicações possíveis ou prováveis.

Ao utilizar a figura do leitor para expressar essa expectativa, o projeto encarrega o jornalista de uma responsabilidade maior, uma vez que não é apenas a empresa que está exigindo essa atitude, o que permite deduzir que recorrer ao leitor é um recurso argumentativo que favorece ampliar a responsabilidade e as chances de a prescrição ser atendida. Isso se faz colocando o leitor como autor da prescrição e, por extensão, do próprio 
projeto: o autor se apropria de uma possível palavra do outro, o leitor, este sim, o interlocutor direto do jornalista.

No projeto de 84, a Folha utiliza o termo "legitimidade" para se apropriar de um "mandato" conferido pelo leitor, que teoricamente lhe daria o poder de tomar as decisões e as prescrições expressas nos projetos.

Temos um mandato expresso de quase 300 mil compradores de jornal, renovado a cada dia nas bancas e na não suspensão de assinaturas, para levar esse Projeto adiante. É em nome dos quase 900 mil leitores reais, que estão por trás daqueles 300 mil, que fazemos a Folha. É o mandato conferido implicitamente por eles e que eles podem cassar a qualquer dia que legitima as nossas decisões.

Outro exemplo é encontrado no projeto de 85, quando a Folha explica a sua opção pelo apartidarismo: "o jornal precisa ser apartidário porque a base de leitores é pluripartidária". Ou, então, no projeto de 86-87: "A expectativa do leitor é que o jornal se diferencie pela excelência do produto, o que exige perfeccionismo em todas as fases do trabalho".

\section{O LEITOR}

No quadro teórico do Círculo de Bakhtin, as relações dialógicas devem ser entendidas como os processos de interlocução em que o outro não é visto como um simples receptor. A enunciação que se estabelece, citando Voloshinov (1976, p. 112), é o produto da interação de dois indivíduos socialmente organizados e, mesmo que não haja um interlocutor real, ele pode ser suposto como um representante médio do grupo social ao qual pertence o locutor.

A própria definição que o Círculo de Bakhtin propõe para enunciado já contém a presença do outro. Diz Voloshinov (1999, p. 112):

A palavra dirige-se a um interlocutor: ela é função da pessoa desse interlocutor: variará se se tratar de uma pessoa do mesmo grupo social ou não, se esta for inferior ou superior na hierarquia social, se estiver ligada ao locutor por laços sociais mais ou menos estreitos [...].

Como pensar, então, a relação dialógica entre um jornal e seu público? No caso de um jornal impresso, como a Folha, cabe também perguntar: o jornal é aquele que fala sem interlocução, que traz em suas páginas informações, opiniões, omissões, pontos de vista, independentemente dos pontos de vista, opiniões e omissões de quem o lê? Num primeiro momento, poder-se-ia dizer que sim, uma vez que é o jornal que, aparentemente sem pedir licença, entra diariamente na casa de seu leitor.

Nesse sentido, ficaria difícil falar em interlocução. Mas não é o que deveras acontece. No caso da Folha e dos demais veículos de comunicação impressos da iniciativa privada, o primeiro indício de interlocução real é o pagamento pelo produto jornal. Nesse sentido, o leitor seria um consumidor e a Folha, uma mercadoria.

Essa concepção possibilita pensar que, por meio do pagamento, o leitor dá a sua primeira permissão para que o jornal se posicione desta ou daquela forma, algo como um salvo-conduto ideológico, segundo faz entender a Folha. Foi, afinal, o leitor quem permitiu que, diariamente, no caso dos assinantes, estabelecesse-se esse ato de interlocução. 
O leitor é, em tese, aquele que garante a existência do jornal. A notícia, modernamente considerada uma mercadoria, adquiriu esse status não apenas porque passou a ser objeto de consumo e, portanto, descartável, mas também porque é o produto que, na sociedade industrial de consumo, deve ser projetado a partir da necessidade que os consumidores têm dele. Conforme acentua Frias Filho, secretário de Redação e um dos herdeiros do Grupo Folha, "a ideia de que o jornal deveria se nutrir única e exclusivamente do seu mercado foi realmente posta pela empresa em prática e garantiu a ela uma autonomia editorial muito grande" (apud ABREU; LATTMAN-WELTMAN; ROCHA, 2003, p. 365).

Mas quem são os leitores da Folha que permitiram ao jornal crescer de forma autônoma, ao contrário de jornais que precisaram submeter-se ao Estado para sobreviver?

Segundo o Datafolha, em 1988, 28\% dos leitores da Folha tinham mais de 50 anos. Em 2000, seu leitor síntese tinha formação superior, era casado, e o grupo com mais de 50 anos já perfazia $41 \%$ do total dos leitores no estado de São Paulo. Esse movimento teria se dado, sobretudo, pela queda na participação dos mais jovens (até 29 anos).

Em 2001, a Folha identificava o seu leitor médio como pertencente à faixa dos 40 anos. Além disso, esse leitor-síntese teria formação superior, seria casado, estaria empregado no setor formal da economia, teria renda individual na faixa que vai até 15 salários mínimos e familiar que ultrapassa os 30 mínimos. Faria parte da classe A ou B. Seria católico, possuiria TV por assinatura e utilizaria a Internet.

Em 2007 o leitor-síntese da Folha tinha as seguintes características: 90\% pertenciam às classes A e B; 69\% liam revistas e 57\% buscavam notícias na internet.

A comparação com o levantamento realizado em 1997 mostra um declínio na proporção de católicos: embora continuassem sendo a maioria do leitorado, houve uma diminuição de dez pontos percentuais (de 65\% para 55\%) e um aumento dos que se declaravam sem religião (de $10 \%$ para $18 \%$ ). Outras mudanças notadas, nesse ano de 2007 , aconteceram no campo político. Cresceu a desilusão com os partidos - a maioria, 57\%, declarou não ter simpatia por nenhum deles (em 2000, eram 45\%).

Com base em dados dessas pesquisas, a Folha muda, recua ou reforça suas diretrizes. Por identificar, por exemplo, um leitor de nível superior, pode incluir temas mais herméticos ao grande público que os abordados pelos noticiários das emissoras de televisão, por exemplo. Exige de seus jornalistas, porém, a utilização de recursos visuais e de linguagem mais condizentes com públicos que pouco apreciam a leitura, ou que dispõem de pouco tempo para ela. A ênfase na necessidade de didatismo, por exemplo, reforça essa possibilidade. Ao mesmo tempo, num determinado momento, ao propor a transposição de um texto menos informativo e mais analítico, é como se o jornal confiasse mais na capacidade de seu leitor receber uma opinião sem se chocar e/ou sem se deixar levar por ela.

Segundo pesquisa do jornal, esse leitor teria uma visão "mais liberal" (assim mesmo, entre aspas) da sociedade. Nesse sentido, pode-se formular uma primeira pergunta: o leitor lê a Folha porque a Folha é um jornal liberal, ou a Folha é um jornal liberal para agradar seus leitores e, assim, vender seu produto? A Folha desenvolve um jornalismo crítico, apartidário e pluralista, ou é o seu leitor que, preso numa massa amorfa e com identificação da média ponderada, é composto por indivíduos de vários partidos, embora de origens, em sua maioria, neoliberais, de várias opiniões, e crítico, sem dúvida, até porque pertencente a uma faixa da população que conta com renda média alta e com ensino superior?

Vale lembrar que, em seus projetos editoriais, em sua dimensão de manual de conduta voltado aos jornalistas da empresa, a Folha já se dizia liberal desde 1981. Seus projetos preconizam a defesa do mercado, e o jornal coloca o mercado como seu único servo, até mesmo ao chamar seu leitor de consumidor explicitamente. 
De qualquer forma, dado que o objetivo é apontar uma relação de interlocução entre leitor e empresa, vale a pena fazer observar alguns aspectos históricos que demonstram uma característica, entendida aqui como padrão do jornal, de antecipar tendências de seus leitores e assimilá-las.

Historicamente, a Folha é reconhecida como uma empresa com característica de antecipar tendências e amoldar-se a novas circunstâncias sempre que os fatos assim o exigissem. Seus sucessivos projetos editoriais e gráficos mostram essa faceta.

Muitas fases do jornal mostram isso, mas a mais conhecida foi certamente a defesa do ao movimento das Diretas Já. A Folha vinha de uma fase, durante a ditadura militar, em que seu comportamento frente à política brasileira foi considerado, inclusive por seus diretores, "anódina". Não houve, como foi o caso do jornal O Estado de São Paulo, nenhum tipo de enfrentamento, discordância ou qualquer outro posicionamento desse tipo nos anos de ditadura militar.

Esse posicionamento do jornal - ou falta dele - foi mudando gradativamente a partir da fase de abertura política do país, e ficou consolidada por ocasião do movimento pelas Diretas, quando o jornal não apenas noticiou à exaustão os fatos relacionados ao movimento, mas se posicionou francamente favorável a ele, sendo que, no dia da votação da emenda Dante de Oliveira, publicou, na sua primeira página, foto de dezenas de representantes da sociedade civil, sobre o piso de cobertura do edifício do jornal, que se posicionavam a favor das Diretas. Foi a fase do crescimento mais expressivo da história do jornal, mas ainda assim, pode-se perguntar: o jornal aderiu a uma posição política e, por isso, arrebatou novos leitores ou ele apenas curvou-se a um anseio irrefreável e irreversível que vinha das ruas?

Como enunciar é manifestar valores, é importante atentar para o fato de que o único projeto que utiliza o termo "consumidor", antes do de 97 , é o de 85 e, mesmo assim, para referir-se ao tipo de "prestação de serviços" que não se confunde com o jornalismo clássico. No projeto de 85 , a menção é feita quando o documento se refere às variadas editorias do jornal, ao tratar dos seus suplementos, como os de "Veículos", "Turismo", "Empregos", etc.:

Nos suplementos, a dimensão do serviço deve desfrutar de um predomínio decidido. Eles representam prestação de serviço diretamente do consumidor: informações sobre imóveis ou empregos, viagens ou passeios turísticos, produtos eletrônicos, automóveis, bens e serviços ligados à vida e à casa moderna. (PE 85)

Tal não é o mesmo enfoque do PE de 97: ali, usa-se o termo "consumidor" para referir-se ao leitor, porém numa perspectiva de que o leitor é aquele que consome a mercadoria "notícia", "informação", "opinião", "análise".

O termo é utilizado nos trechos do projeto abaixo transcritos:

Tais grupos [empresas locais que se associam a investimentos estrangeiros] tendem a acumular poder e por isso sofrem restrições mesmo nos países onde a legislação econômica é considerada liberal. No entanto, sendo sua lógica a do mercado, voltada para o atendimento de demandas que remunerem, o risco parece ser menos o de manipulações conspiratórias contra o público do que o de uma atitude, crescente nos meios de comunicação em geral, que se limita a espelhar as expectativas de um consumidor estatisticamente médio. (grifo nosso) (PE 97) 
Fala-se em direito à não-informação, sintoma de um público que se ressente não já da falta, mas de um excesso inassimilável de dados, de uma verdadeira cacofonia da comunicação.

A proliferação da oferta acirra a disputa pelo tempo do consumidor. (grifo nosso) (PE 97)

Há uma grande massa de informações, para não mencionar o trabalho analítico em torno delas, que o consumidor não precisa receber em ritmo mais frequente do que o diário. (grifo nosso) (PE 97)

Pode-se objetar que parte desse crescimento não decorreu do aumento dos leitores, mas de consumidores atraídos por promoções ou descontos vinculados à compra do produto. (grifo nosso) (PE 97)

O último excerto refere-se à prática, adotada pela Folha, de incorporar à venda dos exemplares produtos como enciclopédias, dvds, cds, coleções de literatura e outros atrativos para seu público, novamente uma forma de se modernizar e de incorporar novidades mercadológicas ao processo jornalístico. Tal característica do jornal, a de amoldar-se às circunstâncias, está relacionada de maneira direta a uma prática mercadológica que utiliza preceitos do jornalismo, tais como isenção, imparcialidade e outros, como estratégia de venda de um produto: a informação.

\section{CONCLUSÃO}

Apesar da pluralidade manifestada por seus sucessivos PEs (o jornal consegue o feito de reunir colunistas de origens político-ideológicas díspares), a Folha tem um objetivo comum na sua proposta: o mercado. Os projetos, apesar de defenderem princípios caros aos ideais do jornalismo - como os da isenção, do apartidarismo, da objetividade, da fidelidade da informação, da crítica, etc. - sempre procuram lembrar ao jornalista que sua atividade está sujeita às leis do mercado, nesses termos.

Esse aspecto - apesar da carga negativa que certamente o termo contém, numa atividade como o jornalismo, na qual ganha credibilidade o veículo que se distancia do mercado, porque essa atitude está relacionada com a característica de isenção - também legitima a opção da Folha, manifestada em um de seus slogans mais conhecidos, de ter "o rabo preso com o leitor".

A escolha por um padrão de atuação, que identifica leitores com "consumidores", permite ao jornal declarar-se como atividade empresarial e não cultural, como muitas vezes é encarado o jornalismo. Silva, considerado por Azenha um "americanófilo" (AZENHA, 1991, p. 13), ressalta que é:

[...] interessante comparar o período histórico em que se deu o início da efetiva profissionalização das redações nos jornais americanos e quando ela ocorre no Brasil. A conclusão a que se vai chegar é que essa é uma das últimas áreas em que a influência americana se faz sentir. Ela ocorre muito tempo depois da influência na filosofia, no estilo, na legislação e na ética.

$\mathrm{Na}$ verdade, em 1990, ela ainda está em seus primórdios, como se pode observar na polêmica que a implantação do "Projeto Folha" causou no jornal Folha de S. Paulo. O fato de se encarar com naturalidade que o jornal é um produto de mercado e que sua produção deve obedecer a princípios de

organização em muitos aspectos similares aos de qualquer indústria, ainda é 
considerado por boa parte dos jornalistas brasileiros como blasfêmia. Nos Estados Unidos, o consenso em torno dessa constatação já estava tão estabelecido no princípio deste século, que Edwin Shuman podia escrever em 1903 sem problemas que "o jornal moderno é uma empresa de negócios e os homens que o dirigem são movidos em grande parte pelos mesmos motivos dos homens que conduzem uma loja de departamentos". (SILVA, 1991, p. 138-139)

O depoimento de Silva corrobora o esforço demonstrado pela Folha, nos sucessivos projetos editoriais, em sua posição de empresa, para convencer seus jornalistas a aceitarem essa postura de sujeição ao mercado. Portanto, a história de mudanças que marcou o jornal, desde 1921, com sua criação sob o nome Folha da Manhã, até sua assunção como empresa que identifica seu leitor como consumidor, pode ser vista mais como um reflexo de mudança da sociedade brasileira e uma estratégica mercadológica do que uma crença em formar opiniões sob os auspícios de valores éticos, políticos e morais.

A Folha, assim como outros veículos de comunicação, é responsável por veicular, numa corrente de transmissão em que múltiplas vozes se misturam (o mercado, a política, os poderes instituídos, os componentes de sua esfera de atividade, o leitor), sua forma de enxergar o mundo e seus processos, ou ainda de adotar como sua a forma como seus leitores enxergam o mundo e os processos dos quais participam e que o constituem. As pressões que essas vozes exercem na direção da Folha se manifestam nos projetos que, por sua vez, aparecem nas páginas do jornal.

Pela análise dos PEs, pode-se, ainda, observar que o jornal entende sua atividade como uma empresa enxerga a mercadoria: com orgulho de estar fazendo o melhor para vender mais, de acordo com os anseios de seus consumidores, sem, no entanto, jamais abrir mão daquilo em que acredita, ou seja, a manutenção de um controle de qualidade compatível com a sua relevância no cenário nacional, assim como o dono de uma loja de departamentos agiria em relação ao produto que vende.

Apesar de sua ênfase no mercado, a Folha diz não permitir-se a utilização de recursos chamados sensacionalistas e utilizados por uma parte da imprensa, com o objetivo único de vender jornal, pelo menos em se tratando do principal jornal da empresa; basta lembrar que a Empresa Folhas foi proprietária, durante anos, do jornal Notícias Populares, um ícone do jornalismo sensacionalista no país.

O que nem sempre transparece é que ser identificada com o jornalismo sério, que evita adjetivos e sensacionalismos, com textos objetivos e imparciais, etc., não a faz contrapor-se, em tudo, ao jornal sensacionalista, já que a motivação de ambos é atrair o leitor, um com o apelo fácil do sexo e do sangue e outro com o status de ser restrito a um público selecionado, exigente e politicamente correto.

No discurso dos projetos, o jornal possui um mandato conferido pelo leitor, sobretudo quando afirma que é ele quem define sua política editorial, que lhe dita posturas e formas de cobertura, e isso, para a Folha, traduz-se em signo de independência editorial.

\section{REFERÊNCIAS}

ABREU, A. A.; LATTMAN-WELTMAN, F.; ROCHA, D. (org.). Eles mudaram a imprensa - Depoimentos ao CPDOC. Rio de Janeiro: Editora FGV, 2003. 
AZENHA, L. C. Apresentação. In: SILVA, C. E. L. O adiantado da hora: a influência americana sobre o jornalismo brasileiro. São Paulo: Summus, 1991.

BAKHTIN, M. Marxismo e filosofia da linguagem: problemas fundamentais do método sociológico na ciência da linguagem. São Paulo: Hucitec, 1999.

Estética da criação verbal. São Paulo: Martins Fontes, 2000.

Questões de literatura e de estética. São Paulo: Ed. Unesp, 1998.

CAVALCANTI, J. R. No "mundo dos jornalistas": interdiscursividade, identidade, ethos e gêneros. 2006. Tese (Doutorado em Linguística) Universidade Estadual de Campinas.

FOLHA DE S. PAULO. Projeto Editorial 1981. Disponível em:

http://www1.folha.uol.com.br/institucional/projeto-1981.shtml . Acesso em: 25 maio 2010.

Projeto Editorial 1984 .Disponível em:

http://www1.folha.uol.com.br/folha/conheca/linha editorial.shtml . Acesso em 25/05/2010.

Projeto Editorial 1985-1986 .Disponível em:

http://www1.folha.uol.com.br/folha/conheca/linha editorial.shtml. Acesso em 25/05/2010.

Projeto Editorial 1986-1987 .Disponível em:

http://www1.folha.uol.com.br/folha/conheca/linha_editorial.shtml . Acesso em 25/05/2010.

Projeto Editorial 1988-1989 .Disponível em:

http://www1.folha.uol.com.br/folha/conheca/linha_editorial.shtml . Acesso em 25/05/2010.

Projeto Editorial 1997 .Disponível em:

http://www1.folha.uol.com.br/folha/conheca/linha editorial.shtml . Acesso em 25/05/2010.

RIBEIRO, J. C. Sempre alerta: condições e contradições do trabalho jornalístico. São Paulo: Olho d'Água, 2001.

SILVA, C. E. L. Mil dias: seis mil dias depois. São Paulo: Publifolha, 2005.

Cultural, 1988.

Mil dias: os bastidores da revolução em um grande jornal. São Paulo: Trajetória

Mil Dias: os bastidores da revolução em um grande jornal. 1987. Tese (Livredocência apresentada à Escola de Comunicações e Artes, USP), São Paulo, 1987.

VOLOSHINOV, V. N. (1926). Discurso na vida e discurso na arte. Trad. de Carlos Alberto Faracco e Cristóvão Tezza de Discourse in life and discourse in art: concerning sociological poetics. In: . (1976). Freudianism. New York: Academic Press (mimeo), 2000.

Recebido em: 07/02/12

Aprovado em: 15/05/12 